\title{
Frequent Users of Rural Primary Care: Comparisons With Randomly Selected Users
}

\author{
Lewis E. Mebl-Madrona, $M D, P b D$
}

Background: Frequent users of primary care have not been adequately characterized. The unique characteristics of this population was sought-why they come so often, what their care costs, and whether psychosocial factors play a role in their high utilization of health care.

Methods: The billing system of a rural primary care clinic was used to find the frequency of visits for all patients attending the clinic for the previous 12 months. The 211 most frequent visitors were selected. A comparison group of 250 patients was drawn from the billing records using a random number generator. Charts were reviewed to compare diagnoses (by frequency), number of procedures, amount billed for care, amount received from those billings, number of psychotropic medications prescribed, and response to medication. A subgroup of each group was interviewed to confirm chart review findings and to inquire about personal reasons for coming to the clinic.

Results: Compared with patients who were random users, patients who were frequent users were more likely to come from the younger and older age groups, they averaged significantly more emergency department visits and visits to other specialists $(P<0.0001)$, and they had more mental health problems diagnosed $(P<0.01)$. Significantly more frequent users were insured by Medicaid and fewer were insured by Medicare. They had more detailed office visits and more laboratory tests. They received twice as much psychotherapy and had a higher percentage of problem-focused office visits. Chart audits and interviews of selected patients revealed that many nonmedical reasons were related to visits in addition to psychosocial stressors.

Conclusions: Nonmedical factors are important among the most frequent users of a primary care clinic. Proposals to improve care for frequent users should consider the psychosocial needs of this population. (J Am Board Fam Pract 1998;11:105-15.)

In these days of discussion about health care reform, it seems logical that physicians should know more about frequent users of health care services. Little, if any, data exist on frequent users to primary care clinics and how best to meet their needs. Accordingly, this study was conducted to explore the special characteristics of the most frequent users of a family practice clinic.

The most frequent users of care can be a problem group who will not necessary subscribe to the rational assumptions made by some health care reformers. Their needs might flow in counterintuitive directions as they seek help for individual and family suffering through their interactions with

Submitted, revised, 21 August 1997.

From the Native American Research and Training Center, Department of Family and Community Medicine, University of Arizona College of Medicine, Tucson. Address reprint requests to Lewis E. Mehl-Madrona, MD, Center for Complementary Medicine, Shadyside Hospital, University of Pittsburgh Medical Center, 5230 Center Ave, Pittsburgh, PA 15232 . front office staff, fellow patients in the waiting room, clinic nurses and aides, and finally the health care providers. Encounters with these patients might fall more often into the 60 percent of physician office visits that fail to result in a confirmed biologic diagnosis. ${ }^{1,2}$

A study by John et $\mathrm{al}^{3}$ compared difficult patients with randomly selected patients of a family practice center. When physicians were asked to pick out those patients whose care they considered difficult, the patients were older, more often divorced or widowed, and more likely to be women. They had more acute and chronic problems, took more medications, and had more $x$-ray examinations, blood tests, physician referrals, and visits to the family practice center. This group did not dif- fer from the randomly selected group in household composition, payment status, or provider continuity. In another study of 627 adult primary care patients in four clinics, 15 percent were reported to be difficult. ${ }^{4}$ Difficult patients were almost three times more likely to have a mental dis- 
order. Being difficult was particularly strongly associated with having diagnosis of a somatoform disorder, panic disorder, dysthymia, generalized anxiety disorder, or alcohol abuse or dependence. Increased functional impairment, higher health care utilization, and lower satisfaction with care were associated with difficult patients, whereas demographic characteristics and physical illnesses were not.

$\mathrm{McF}$ arland et al, ${ }^{5}$ who studied frequent users of a prepaid group practice health maintenance organization (HMO) in 1985, found that 13 percent of adult members accounted for 31 percent of the total office visits to physicians, 35 percent of hospital admissions, and 30 percent of outpatient surgical services. The most frequent reasons for office visits was for treatment or follow-up of chronic medical conditions. Patterns of utilization were unrelated to marital status, income, occupation, perceived social class, smoking, or alcohol use. The consistently high users were more likely to perceive their health status as fair or poor and to report a higher number of physical symptoms. They were also more likely to be characterized by a higher degree of psychologic distress, especially depression. Contact with the mental health department comprised less than 1 percent of their total visits to the HMO. Only 13 percent of high users made at least one mental contact during the study period.

Suggestions have been made that these frequent users have among them more persons with psychiatric disorders than would be encountered in a randomly selected population. Barsky et al $^{6}$ investigated psychiatric disorders (depression and hypochondriasis), somatic symptoms, medical morbidity, and the utilization of ambulatory medical services among 92 general medical outpatients. Medical utilization correlated with the number of somatic symptoms reported $(r=0.49$, $P=0.0001)$, depressive symptoms $(\mathrm{r}=0.34, P=$ 0.001 ), and the number of medical diagnoses and was related to hypochondriacal attitudes $(r=0.52$, $P=0.0001)$ and depression $(\mathrm{r}=0.51, P=0.0001)$. In stepwise multiple regression analyses, the number of medical diagnoses accounted for 30 percent of the variance in medical utilization. Somatic symptoms were the second most powerful predictor, increasing $R^{2}$ to 0.469 . The next best predictors were two hypochondriacal attitudes and having a major psychiatric diagnosis recorded in the medical record. This five-step model explained 56 percent of the variance. Depression, disease fear, and bodily preoccupations were also important predictors of utilization. Somatic symptoms were viewed as a final common pathway through which emotional disturbance, psychiatric disorders, and organ disease all express themselves that prompted patients to visit their physicians.

Katon et al $^{7}$ concluded that 25 to 75 percent of visits to primary care physicians were primarily due to psychosocial stress manifested by somatic complaints. Approximately 70 percent of patients with primary or secondary diagnoses of emotional disorders gave a somatic complaint as the reason for their visits to physicians. Among the most common complaints were constitutional symptoms, headache, dizziness, abdominal or extremity pain, and requests for checkups. In a later study of 767 high users of health care, ${ }^{8} 51$ percent were determined to be distressed by (1) high scores on the Symptom Checklist (SCL) anxiety and depression scales, (2) high scores on the SCL somatization scale, or (3) their primary care physician. These distressed high users were found to have numerous chronic medical problems and considerable limitations of activities caused by illness. In the previous year they averaged 15 medical visits and 15 telephone calls to the clinic. When the Diagnostic Interview Schedule was administered to 119 distressed high users who had been randomly assigned to a psychiatric consultation, 23.5 percent had major depression, 16.5 percent had dysthymic disorder, 21.8 percent had generalized anxiety disorder, and 20.2 percent had somatization disorder. Two thirds had a lifetime history of major depression.

Somatization frequently underlies visits to primary care physicians and is most often associated with depression, anxiety, and somatoform disorders in primary care populations. Depression is not recognized or treated in roughly 18 to 50 percent of affected primary care patients. 9,10 The most common mental disorder in the general population after substance abuse and anxiety, ${ }^{11}$ depression is one of the most common disorders underlying somatization in primary care. ${ }^{12-15} \mathrm{De}$ pressed patients can selectively focus on the somatic manifestations of their disease and ignore, or not experience, affective or mood disturbance. ${ }^{13}$ These patients often seek care from their 
primary care physicians for classic depressive somatic complaints or nonspecific cardiopulmonary and gastrointestinal complaints or localized pain, lacking the symptoms of depressed affect. $\mathrm{Pa}$ tients with this masked depression might lack the ability to label and report emotions (alexithymia, or inability to reveal feelings using usual words or language). ${ }^{16}$

\section{Methods}

The clinic was a rural family practice clinic serving a small town (population approximately 9600) in northern New England. No other health centers existed in the town. The nearest hospital was 15 miles away.

Data stored in a computerized medical record system consisted of information about each patient's visit, the primary and secondary diagnoses, the clinic provider, the charge for the service, the intermediary to whom the service was billed (including secondary carriers), and the ultimate fate of the claim (collection, write-off, payment, etc). A permanent problem list and a temporary problem list were available on the computer. A list of all providers seen within the nearby university system was also available. For patients seen in the primary care clinic, the record of the visit was available on the computer. Visit records were not available for patients seen in specialty clinics.

Oxman et $\mathrm{al}^{16}$ has found that family physicians have tended to underdiagnose somatoform disorders, anxiety disorders, and depression. In this study the same group of physicians cared for all patients; if there was an underdiagnosis bias, it was applied consistently to all patients.

Data from the 211 patients who were seen in the clinic most frequently were abstracted from the computer. For comparison purposes the same data were obtained for 250 randomly selected patients who had been seen during the month of April. It was assumed that April would not be particularly different from any other month. Generally, health care providers who had been at the clinic for a number of years agreed that this was a reasonable assumption.

Some of the frequent users were also part of the random-user group. The random-user comparison group thus represented a cross-section of all users and formed a more conservative comparison group than one in which frequent users had been eliminated. This comparison group was more appropriate for answering whether frequent users differed in any important ways from the class of all users.

\section{Statistical Analysis}

A statistical analysis of the data was generated using the Systat package ${ }^{17}$ as designed for the Macintosh computer. Differences between groups were evaluated using the chi-square test of independence. The assumptions for this test were met by the data in that (1) there was only one data entry for each patient in the sample (diagnosis present or absent), (2) the categories were mutually exclusive and exhaustive, and (3) there were no expected frequencies of zero. The test is distribution free or nonparametric. The t-test was used to evaluate differences in means for number of visits for the two groups. Before doing so, the Kolmogorov-Smirnov two-sample test was used to determine that the two different samples were apparently drawn from the same population. Although both samples were skewed in their distribution, the graphed distribution appeared similar. The t-test was used because of its simplicity and its robustness to moderate violations of its assumptions. ${ }^{18}$ The $t$-test for related samples was used. The Mann-Whitney $U$ test for nonparametric distributions showed no difference in results from the simpler (and more readily understood) $t$ test. For all analyses, a probability of $P<0.05$ was accepted as significant.

Physicians dictated chart notes, which were typed into the medical record computer system. Chart notes of patients selected for the year in question were audited for medications prescribed, response to the medications, and health care providers' assessment of status changes from visit to visit (improved, no change, worse). A simple scale was used to determine overall response to psychiatric medication. Any improvement was scored as +1 and any worsening or side effects were scored as -1 . No change or no mention was scored as 0 . The scores were totaled, with a negative score indicating worsening during the year, and a positive score indicating improvement.

Overall patient status, which was assessed in the same manner, was more encompassing than response to medication, as it included medication response as well as any other mention of improvement or deterioration for any reason. Again, sim- 
Table 1. Age Comparison Between Frequent Users and Random Users of Medical Care in a Rural Health Clinic.

\begin{tabular}{lccr}
\hline Age, years & $\begin{array}{c}\text { Frequent Users } \\
\%\end{array}$ & $\begin{array}{c}\text { Random Users } \\
\%\end{array}$ & $P$ Value \\
\hline$<5$ & 15 & 9 & $<0.05$ \\
5 to 12 & 4 & 7 & NS \\
13 to 20 & 8 & 4 & $<0.05$ \\
20 to 29 & 8 & 13 & NS \\
30 to 39 & 15 & 21 & NS \\
40 to 49 & 14 & 18 & NS \\
50 to 59 & 10 & 14 & NS \\
60 to 69 & 18 & 10 & $<0.05$ \\
$70+$ & 8 & 4 & $<0.05$ \\
\hline
\end{tabular}

NS - not significant.

ple summation was used to obtain a score for the year.

Subgroups of 75 of the 211 frequent users and 51 of the randomly selected users were interviewed informally by telephone or in person at their clinic visits. Because of the frequency of these patient's visits, it was relatively easy to interview a subgroup of patients to determine some of their reasons for coming to the clinic. Patients were asked the following questions:

1. Why they were in the clinic that day, or why they had come to the clinic for their most recent visit

2. What they liked about coming to the clinic
3. What they disliked about coming to the clinic

4. What, if any, stressful life events were occurring in their life at the time

5. What important was happening to any of the other family members

\section{Results}

The 211 frequent users had a mean of 15 visits per year (SD 6) compared with a mean of 6 visits per year (SD 2) for the 250 random users, significant at $P<0.001(t=3.65, d f=459)$. The frequent users had an average of 12 emergency department (including urgent care) visits per year (SD 6) compared with 4 emergency department visits per year (SD 2) for the random visitors (including urgent care), significant at $P<0.001(t=3.23)$. Frequent users had 20 visits per year to other specialist physicians within the larger health system (SD 6) to which the clinic belonged compared with an average of 5 visits to other physicians within the university system (SD 3) for random users, significant at $P<0.001(t=3.60)$. The average total medical contacts per year for the frequent users was 47 compared with 15 for the randomly selected users.

The mode for number of clinic visits per year for frequent users was 12 (range 6 to 61) and was 4 for random visitors (range 1 to 61). The mode for total number of medical contacts for frequent

Table 2. Ten Most Common Psychiatric Diagnoses and Percentage of Associated Visits Encountered Among Frequent Users $(n=211)$ and Randomly Selected Users (250) of a Rural Health Clinic.

\begin{tabular}{|c|c|c|c|c|c|c|}
\hline Diagnosis & $\begin{array}{c}\text { Frequent } \\
\text { Users } \\
\text { With } \\
\text { Diagnosis } \\
\text { No. }\end{array}$ & $\begin{array}{c}\text { Visits } \\
\text { Associated } \\
\text { With } \\
\text { Diagnosis } \\
\text { (\%) }\end{array}$ & $\begin{array}{l}\text { Random } \\
\text { Users } \\
\text { With } \\
\text { Diagnosis } \\
\text { No. }\end{array}$ & $\begin{array}{c}\text { Visits } \\
\text { Associated } \\
\text { With } \\
\text { Diagnosis } \\
\text { (\%) }\end{array}$ & $\chi^{2}$ & $\begin{array}{c}P \\
\text { Value }\end{array}$ \\
\hline Adjustment reaction & 117 & 3.70 & 17 & 1.12 & 131.35 & $<0.001$ \\
\hline Anxiety states & 74 & 2.34 & 26 & 1.71 & 41.00 & $<0.01$ \\
\hline Depressive disorder & 73 & 2.31 & 11 & 0.73 & 74.02 & $<0.01$ \\
\hline Neurotic depression & 55 & 1.74 & 23 & 1.52 & 23.15 & $<0.01$ \\
\hline $\begin{array}{l}\text { Adjustment reaction-mixed } \\
\text { emotional features }\end{array}$ & 41 & 1.30 & 11 & 0.73 & 25.83 & $<0.01$ \\
\hline Panic disorder & 19 & 0.60 & 15 & 0.99 & & \\
\hline $\begin{array}{l}\text { Adjustment reaction- } \\
\text { emotion/conduct }\end{array}$ & 16 & 0.51 & 1 & 0.07 & 16.66 & $<0.01$ \\
\hline $\begin{array}{l}\text { Adjustment reaction- } \\
\text { physical symptoms }\end{array}$ & 7 & 0.22 & 0 & 0.00 & 8.42 & $<0.05$ \\
\hline Hypochondriasis & 6 & 0.19 & 0 & 0.00 & 7.20 & $<0.05$ \\
\hline Other combined & 32 & 1.02 & 19 & 1.27 & 6.66 & $<0.05$ \\
\hline Total diagnoses & 440 & & 123 & & & \\
\hline
\end{tabular}


Table 3. Number of Visits Associated With Specific Diagnoses Among Frequent Users and Randomly Selected Users of a Rural Health Clinic by Diagnosis

\begin{tabular}{|c|c|c|c|c|}
\hline Diagnosis & $\begin{array}{l}\text { Associated Visits } \\
\text { for Frequent Users } \\
\text { No. (\%) }\end{array}$ & $\begin{array}{l}\text { Associated Visits } \\
\text { for Random Users } \\
\text { No. (\%) }\end{array}$ & $\chi^{2}$ & $P$ Value \\
\hline Allergic rhinitis & $349(11.05)$ & $47 \quad(3.10)$ & 83.79 & $<0.01$ \\
\hline Adjustment reaction, NOS & $117(3.70)$ & $17(1.12)$ & 24.64 & $<0.01$ \\
\hline Acute sinusitis, NOS & $109(3.45)$ & $80 \quad(5.27)$ & 8.71 & $<0.05$ \\
\hline Otitis media & $104(3.29)$ & $13(0.86)$ & 24.98 & $<0.01$ \\
\hline Abdominal pain & $85 \quad(2.69)$ & $38(2.50)$ & & \\
\hline Headache & $75 \quad(2.37)$ & $50 \quad(3.30)$ & & \\
\hline Hypertension & $74(2.34)$ & $42(2.77)$ & & \\
\hline Anxiety states & $74(2.34)$ & $26(1.71)$ & & \\
\hline Depressive disorders & $73(2.31)$ & $11(0.73)$ & 14.65 & $<0.01$ \\
\hline Acute pharyngitis & $73 \quad(2.31)$ & $31(2.04)$ & & \\
\hline Bronchitis, NOS & $66(2.09)$ & $13(0.86)$ & 9.41 & $<0.05$ \\
\hline Arteriosclerotic cardiovascular disease & $65(2.06)$ & $22(1.44)$ & & \\
\hline Emphysema, NEC & $58(1.84)$ & $22(1.44)$ & & \\
\hline Neurotic depression & $55(1.74)$ & $6(0.39)$ & 14.45 & $<0.01$ \\
\hline Diabetes with manifestations, NEC, type II & $53(1.68)$ & $16(1.05)$ & & \\
\hline Urinary tract infection, NOS & $53(1.68)$ & $20(1.31)$ & & \\
\hline Backache, NOS & $50(1.58)$ & $11(0.69)$ & 5.88 & $<0.05$ \\
\hline Acute upper respiratory tract infection, NOS & $47(1.49)$ & $20(1.33)$ & & \\
\hline Normal pregnancy & $45 \quad(1.42)$ & $18(1.19)$ & & \\
\hline Diabetes, uncomplicated, type II & $42(1.33)$ & $15(0.99)$ & & \\
\hline Adjustment reaction mixed emotional & $41(1.30)$ & $5(0.32)$ & 9.89 & $<0.05$ \\
\hline Total visits associated with above diagnoses & $1746(54)$ & $548 \quad(34.4)$ & & \\
\hline Total visits & 15/person & $6.1 /$ person & & \\
\hline
\end{tabular}

Note: Patients typically have more than one diagnosis.

ICD - International Classification of Diseases, ed 9, NOS - not otherwise specified, NEC - not elsewhere classified.

users was 22 and was 8 for randomly selected users. Frequent users were more likely to be younger than 5 years, teenagers, or older than 60 years (Table 1).

Psychiatric conditions were diagnosed more often among the frequent users, including adjustment disorders, anxiety states, depressive disorders, hypochondriasis, and all other combined diagnoses (Table 2). Only the rate of panic disorder was not significantly different between the two groups. Sixty-three percent of frequent users (133 patients) had at least one psychiatric condition diagnosed during the year of the study period, whereas only 14 percent of randomly selected patients had a psychiatric condition diagnosed $(P<$ $.001)$ during this same year. For the frequent users, 133 patients accounted for a total of 440 psychiatric diagnoses. Only 19 percent $(25 \mathrm{pa}$ tients) had one diagnosis. The most common pairing of diagnoses was anxiety and depression;
82 percent (63 patients) with anxiety diagnoses were also considered to be depressed on at least one occasion.

Psychiatric disorders were encountered more often among the 10 most common diagnoses for frequent users and occurred more often than among randomly selected users (Table 3). Frequent users had allergic rhinitis, adjustment disorders, sinusitis, otitis media, depression, bronchitis, and backache recorded more often.

Psychiatric diagnoses were not among the 10 most common diagnoses of randomly selected users. Randomly selected users had sinusitis significantly more often than frequent users, as well - as arteriosclerotic cardiovascular disease, diabetes, bronchitis, and routine gynecologic examinations (without pathologic diagnoses). They were less afflicted with allergic rhinitis (Table 4).

Frequent users were significantly more likely to be insured through Medicaid and CHAMPUS 
Table 4. Number of Visits for 10 Most Common Diagnoses Among Randomly Selected and Frequent Isers of Rural Care $(n=1518$ and 3159$)$ visits, respectively).

\begin{tabular}{|c|c|c|c|c|}
\hline Diagnosis & $\begin{array}{c}\text { Ramklom Users } \\
\text { No.(\%) }\end{array}$ & $\begin{array}{c}\text { Frequent lisers } \\
\text { No.(1\%) }\end{array}$ & $\chi^{2}$ & PValue \\
\hline Acute sinusitis & $80(5.27)$ & $109(3 .+5)$ & 8.71 & $<0.05$ \\
\hline Arteriosederotic cardiovascolar discase & $56(3.69)$ & $0.5(2.06)$ & 10.79 & $<0.01$ \\
\hline Diabetes type II, complicated & $52(3.43)$ & $53(1.68)$ & 14.23 & $<0.01$ \\
\hline Ileadiche & $50(3.29)$ & $75(2.37)$ & & \\
\hline Bromchitis & $49(3.2 .3)$ & $60(2.09)$ & 5.51 & $<0.05$ \\
\hline Allergic rhinitis & $+7(3.10)$ & $3+9(11.05)$ & 83.79 & $<0.01$ \\
\hline Hypertension & $42(2.77)$ & $7+(2.34)$ & & \\
\hline Abrominal pain & $38(2.50)$ & $85(2.69)$ & & \\
\hline Gynceologic examination & $36(2.37)$ & $0(0.0)$ & 75.40 & $<0.01$ \\
\hline Dialuetes type II noneomplicated & $35(2.31)$ & $+2(1.33)$ & 0.01 & $<0.0 .5$ \\
\hline
\end{tabular}

Note: patients can have more than one diagnosis.

ICD-9) - International (Jassification of Diseases, ed".

and less likely to be insured through Medicare than were randomly selected patients (Table 5). Randomly selected visitors had more venipunctures, urinalyses, and cholesterol determinations (Table 6); frequent users received more allergy injections and psychotherapy (of 1 -hour or of $1 / 2$ hour duration).

\section{Results of Chart Audit}

Fourteen percent of frequent users were described in clinic visit notes as difficult patients. Family therapy was mentioned as a possible intervention in only 1 percent of patient visits, whereas other psychosocial interventions were recommended 4 percent of the time.

Chart review did not reveal much documented substance abuse (Table 7). Eleven percent of patients were mentioned as possibly abusing prescription drugs. Substances of potential abuse most mentioned in chart review were propoxy- phene (Darvon) and an oxycodone-acetaminophen combination (Percocet). Seven percent of random users were using controlled substances compared with 22 percent of frequent users $(P<$ $0.01)$. Eight percent of patients were mentioned as using illicit drugs, primarily marijuana. More tobacco use was reported than alcohol. 'Tobacco abuse was mentioned for 27 percent of frequent users compared to 18 percent of random users $(P$ $<0.05)$. Alcohol use was mentioned for 11 percent of patients in both groups. Four percent of frecuent users were mentioned as possibly drinking to excess.

Forty-nine percent of all frequent users were taking some type of psychiatric medication (Table 7). Of those with prescribed medications, only 15 percent were described as improved, whereas 51 percent were described as having side effects or problems with medication or were worse despite medication. Thirty-seven percent of frequent

Table 5. Number of Insurance Billings by Type for Randomly Selected and Frequent Users of Rural Health Care.

\begin{tabular}{|c|c|c|c|c|}
\hline Insurance & $\begin{array}{c}\text { Random Users } \\
\text { No. }(\%)\end{array}$ & $\begin{array}{c}\text { firequent Users } \\
\text { No.(\%) }\end{array}$ & $x^{2}$ & PVilue \\
\hline Medicare & $+30(28.35)$ & $600(19.87)$ & 55.27 & $<0.01$ \\
\hline Medicaid & $26+(17.40)$ & $931(29.47)$ & 78.94 & $<0.01$ \\
\hline Bluc Cross & $251(16.54)$ & $470(1+.88)$ & & \\
\hline Managed care & $180(11.87)$ & $+11(13.01)$ & & \\
\hline Self-paying & $109(6.98)$ & $1.53(4.84)$ & $10.5+$ & $<0.01$ \\
\hline Commercial & $256(16.88)$ & $508(16.08)$ & & \\
\hline Worker's compensation & $29(1.91)$ & $6.5(1.85)$ & & \\
\hline CIIAMPUS, Veterans' Administration & $1(0.07)$ & $22(0.63)$ & 8.34 & $<0.05$ \\
\hline Total & $1520(100.00)$ & $3160(100.01)$ & & \\
\hline
\end{tabular}


Table 6. Most Frequent Procedures Billed For Frequent Users and Randomly Selected Patients in Rural Health Clinic ( $\mathrm{n}=\mathbf{4 1 6 7}$ and 2171 procedures, respectively).

\begin{tabular}{lcccc}
\hline Procedure & $\begin{array}{c}\text { Frequent Users } \\
\text { No.(\%) }\end{array}$ & $\begin{array}{c}\text { Random Users } \\
\text { No.(\%) }\end{array}$ & $\chi^{2}$ & P Valuc \\
\hline Extended office visit & $1751(42.02)$ & $933(42.98)$ & & \\
Allergy injection & $355(8.52)$ & $0(0.00)$ & 1049.46 & $<.001$ \\
Detailed office visit & $316(7.58)$ & $242(11.15)$ & & \\
Venipuncture & $238(5.71)$ & $177(8.15)$ & 14.08 & $<0.01$ \\
Psychotherapy & $232(5.57)$ & $61(2.81)$ & 10.14 & $<0.01$ \\
Dip urinalysis & $111(2.66)$ & $81(3.73)$ & 5.61 & $<0.05$ \\
Problem-focused office visit & $95(2.28)$ & $26(1.20)$ & & \\
Laboratory handling & $69(1.66)$ & $55(2.53)$ & & \\
Complete urinalysis & $61(1.46)$ & $29(1.34)$ & & \\
Urine culture & $57(1.37)$ & $30(1.38)$ & & \\
Hematocrit & $56(1.34)$ & $38(1.75)$ & & \\
Glucose & $50(1.20)$ & $35(1.61)$ & & \\
Rapid test for streptococcal pharyngitis & $46(1.10)$ & $29(1.34)$ & & \\
Human chorionic gonadotropin, qualitative & $46(1.10)$ & $27(1.24)$ & & \\
Cholesterol & $39(0.94)$ & $42(1.93)$ & \\
Wet smear & $27(0.65)$ & $23(1.06)$ & \\
Comprehensive office visit & $26(0.62)$ & $19(0.88)$ & \\
Measles-mumps-rubella vaccination & $22(0.53)$ & $3(0.14)$ & \\
Expanded hospital visit & $21(0.50)$ & $10(0.46)$ & \\
Comprehensive preventive care visit, infant & $20(0.48)$ & $0(0.00)$ & \\
Electrocardiogram & $19(0.46)$ & $15(0.69)$ & \\
Adult diphtheria-tetanus immunization & $19(0.46)$ & $14(0.64)$ & \\
Hemophilus influenza B vaccine & $17(0.41)$ & $0(0.0)$ & \\
Hemoglobin & $15(0.36)$ & $8(0.37)$ & \\
Hospital dilatation and curettage planning & $15(0.36)$ & $5(0.23)$ & \\
Oral poliovirus immunization & $12(0.29)$ & $0(0.0)$ & \\
\hline
\end{tabular}

users were on antidepressant medication, and most had tried three or more medications. Twenty-two percent of total frequent users had been prescribed an antianxiety medication.

\section{Results of Patient Interviews}

Regarding why they had come to the clinic, patients invariably mentioned their physical symptoms. No spontaneous mention was made of emotional stress, stressful life events, family problems or psychiatric symptoms.

More often than random users, frequent users reported liking the opportunity to see friends and family in the waiting room, the opportunity to come to appointments with other patients, and the contact with front office staff and nurses (Table 8). They reported a greater number of puzzling symptoms that were difficult to diagnose and continued to come more often because they remained ill.

For the age groups that had significantly more frequent users (Table 1), the group younger than 5 years manifested otitis media as their major diagnosis. Elementary age children who were frequent users came predominantly for allergy shots. Adolescent frequent users were primarily young women with multiple complaints, but they usually had a primary problem relating to contraception or gynecologic disorders. Frequent users aged more than 50 years predominantly suffered with chronic disease, notably diabetes and heart disease. Correlational analyses revealed no relation between these younger and older patients regarding psychiatric disorders. These problems were almost entirely associated with patients aged 20 through 50 years. Forty-one percent of frequent users were men compared with 47 percent of random users. This difference was not statistically significant. 
Table 7. Results of Chart Audit Regarding Psychoactive Medication, Substance Abuse, and General Trends for Improvement Among Frequent Users ( $n$ - 211) of a Rural Health Clinic.

\begin{tabular}{|c|c|c|}
\hline Chart Audit Items & No. & Percent \\
\hline $\begin{array}{l}\text { Patients with psychiatric } \\
\text { diagnosis prescribed } \\
\text { psychoactive medication }\end{array}$ & 104 & 49 \\
\hline Patients improved & 16 & 15 (of 104) \\
\hline Patients not improved & 35 & 34 (of 104) \\
\hline Patients worse & 53 & 51 (of 104) \\
\hline $\begin{array}{l}\text { Patients prescribed } \\
\text { antidepressants during } \\
\text { past year }\end{array}$ & 78 & 37 \\
\hline $\begin{array}{l}\text { Patients trying } \\
1 \text { antidepressant }\end{array}$ & 7 & 9 (of 78) \\
\hline $\begin{array}{l}\text { Patients trying } \\
2 \text { antidepressants }\end{array}$ & 16 & 21 (of 78) \\
\hline $\begin{array}{l}\text { Patients trying } 3 \text { or more } \\
\text { antidepressants }\end{array}$ & 55 & 71 (of 78) \\
\hline $\begin{array}{l}\text { Patients prescribed } \\
\text { antianxiety medication } \\
\text { during the past year }\end{array}$ & 46 & 22 \\
\hline Patients drinking & 23 & 11 \\
\hline Patients drinking heavily & 9 & 4 \\
\hline Patients using illicit drugs & 10 & 5 \\
\hline $\begin{array}{l}\text { Patients abusing } \\
\text { prescription drugs }\end{array}$ & 24 & 11 \\
\hline
\end{tabular}

When probed, frequent users admitted stressful lives with family problems more often than did random users (Table 9). Compared with their counterparts in the random users group, family members of frequent users were more often fighting or arguing, embroiled in legal problems, challenged by financial problems, caring for other ill family members (some who were dying), dealing with drug or alcohol problems, and struggling with relationship problems.

\section{Discussion}

The strength of this study is also its chief limitation - it was conducted in a working rural family practice where research was not usually conducted and among patients who are not often studied. It is a semiquantitative study, and we hope to generate further controlled research upon this fascinating group of parients.

It is difficult to say how comparable our frequent users and this rural New England clinic are to other US settings. Our frequent users made more visits than those studied by Browne ${ }^{19}$ in a prepaid Canadian Family Practice, whose average number of clinic visits was the same as that of high users studied by Katon et al. ${ }^{7}$ One reviewer suggested that the frequent and random user rates reported here are much higher than national norms. One explanation might be the limited number of health care facilities in this small town (one health center, one hospital 15 miles away), which would make the numbers more reliable. In a more suburban environment it would be easier for patients to visit many clinics, physicians, and hospitals in a manner that would be potentially more difficult to measure. On the other hand, it is possible that this study population consumed more medical care than others, although it is my perception that these patients' health care utilization rates are no different from those of other rural populations I served in New Mexico and Arizona.

Compared with the patients in Browne's study,

Table 8. Likes, Dislikes, and Reasons for Frequent Users (n - 75) and Random Users (n - 51) Coming for Care in a Rural Health Clinic.

\begin{tabular}{|c|c|c|c|c|}
\hline Interview Question, Responses & $\begin{array}{c}\text { Frequent Users } \\
\text { No.(\%) }\end{array}$ & $\begin{array}{c}\text { Random Users } \\
\text { No.(\%) }\end{array}$ & $\chi^{2}$ & $P$ Value \\
\hline \multicolumn{5}{|l|}{ Wbat do you like about coming to the clinic? } \\
\hline Enjoy meeting/seeing friends and family in the waiting room & $23(31)$ & $12(11)$ & 7.35 & 0.05 \\
\hline Like coming with other patients to keep each other company & $31(41)$ & $2(4)$ & 33.51 & $<0.01$ \\
\hline Enjoy the contact with front office staff and nurses & $67(89)$ & $8(16)$ & 74.16 & $<0.01$ \\
\hline Contact with staff is more satisfying than seeing the doctor & $10(13)$ & $1(2)$ & 10.52 & $<0.01$ \\
\hline \multicolumn{5}{|l|}{ Why do you come? } \\
\hline Multiple puzzling symptoms that no one can diagnose & $12(16)$ & $3(6)$ & 9.39 & 0.05 \\
\hline Continue to be sick & $17(23)$ & $3(6)$ & 14.73 & $<0.01$ \\
\hline Chronic illness; doctor tells me to come back & $8(11)$ & $2(4)$ & 6.55 & 0.05 \\
\hline Need shots frequently (including allergy) & $5(7)$ & $1(2)$ & 4.58 & 0.05 \\
\hline
\end{tabular}


Table 9. Percentage of Rural Health Clinic Patients Reporting Family and Life Stress Factors.

\begin{tabular}{|c|c|c|c|c|}
\hline Life Stress Factors* & $\begin{array}{c}\text { Frequent } \\
\text { Users }\end{array}$ & $\begin{array}{c}\text { Random } \\
\text { Users }\end{array}$ & $\chi^{2}$ & $P$ Value \\
\hline Family members arguing or fighting & 78 & 30 & 29.51 & $<0.01$ \\
\hline Legal problems & 10 & 2 & 5.62 & $<0.05$ \\
\hline Money problems & 70 & 24 & 28.60 & $<0.01$ \\
\hline Problems with children misbehaving or getting into trouble & 13 & 12 & & \\
\hline Family illnesses & 66 & 20 & 30.62 & $<0.01$ \\
\hline Family members having drug or alcohol problems & 20 & 12 & 7.66 & $<0.05$ \\
\hline Death or illness of family members & 23 & 13 & 9.42 & $<0.05$ \\
\hline Break-ups or major relationship problems & 24 & 14 & 8.78 & $<0.05$ \\
\hline Percentage reporting none of the above & 9 & 62 & 23.98 & $<0.01$ \\
\hline
\end{tabular}

"Reported in response to the question: During times when you have felt sick in the last year, have you encountered any of the following?

in this study frequent users were both older and younger and more impoverished. The clinic was the only source of health care in this small town and served more unemployed persons than would a prepaid health plan. The town was the poorest in the county and had more poverty-associated problems. The one high school in the town had the lowest scores of all high schools in the county on national standardized achievement tests as well as the lowest rates of graduation and college attendance. ${ }^{20}$

The most obvious categories of frequent use were (1) children with recurrent otitis media and upper respiratory tract infections, (2) patients receiving desensitization injections for allergic rhinitis, (3) young women (aged 13 to 20 years) who sought care for gynecologic and contraceptive problems, and (4) patients older than 60 years who had chronic illnesses. Nevertheless, even when these patients were included in the ranks of frequent users, there was an overrepresentation of psychiatric diagnoses and of headaches and back pain, which could represent somatization. The top 10 diagnoses of randomly selected users contained no psychiatric diagnoses, but psychiatric diagnoses were included in the top 10 diagnoses of frequent users, especially adjustment disorder and depression and anxiety). Given that we assumed the physicians were equally likely to underdiagnose psychiatric disorders in both groups of patients, to the extent that frequent users had more mental disorders, the differences found here could actually be greater.

The relative lack of efficacy of antidepressant medications was startling. It is possible that (1) there was a high occurrence of dysthymic disor- der among frequent users (dysthymia does not typically respond well to antidepressants); (2) somatization disorder or personality disorders were mistaken for depression (neither of the former respond well to antidepressants); or (3) patients were undermedicated. Medication-resistant depressions could also result in more frequent clinic use for somatic complaints. Resolution of these possibilities would require a more careful diagnostic work-up of all frequent users and then psychiatric intervention when diagnoses would warrant medication.

A trend noted in chart review was a tendency to switch medications when one was not effective rather than adding adjunctive medication, prescribing combination therapy (combining a selective serotonin reuptake inhibitor with a tricyclic antidepressant, for example), or prescribing highdose regimens. The great number of medication side effects could suggest an element of personality disorder as well among the frequent users, as patients with personality disorders are more prone to report and dwell on minor symptoms caused by medications.

The answers of patients to our interview questions might generate the best clues to their frequent use-clues that cannot be gleaned from most statistical data on diagnoses, billing, and procedures. Compared with random users, the frequent users more often reported enjoying the waiting room as a place to encounter family and friends, planning appointments together, and enjoying the contact with front office staff and nurses. A greater number of frequent users had multiple, puzzling symptoms. In all, this picture paints a life centered around health care, the rea- 
sons for which being presumably multiple and worthy of further exploration.

The following prototypes of frequent users might help shed further light on our population.

A 42-year-old white man, married, with 2 children, is receiving disability payments related to severe back pain and frequent headaches. $\mathrm{He}$ worked as a finish carpenter at a computer manufacturer 10 miles away and specialized in cleanroom constructions, but he has not worked for the past 7 years. An avid hunter and fisherman, he spends his weekends outdoors with his sons. $\mathrm{He}$ never has headaches while outdoors and frequently supplements the family diet with fish or deer. The patient and his wife have frequent arguments about money and the children. Their oldest son spent 1 year in jail for theft and is on parole. They worry about the younger son following in his brother's footsteps, for he is failing more than one subject in school and smoking more pot than they can condone (though the patient also smokes marijuana). During the interview it becomes obvious that his symptoms worsen when he is worried about and battles with the boys about attending classes or work. His symptoms disappear when he is doing what he loves-hunting and fishing. While doing these activities, neither his back nor his head hurt for extended times.

A 24-year-old woman has frequent medical complaints. Her muscles ache, her joints ache, and she has frequent sore throats. She is convinced that her physicians are not diagnosing her problem properly. Her husband is out of work and she has 4 young children at home. She worries that her husband is having an affair. He drinks heavily at times and is occasionally in legal trouble. Her parents assumed a "you made your own bed" attitude after she married her high school sweetheart against their wishes. After 4 children, they offered her little support and show little interest in their grandchildren.

A 24-year-old, unmarried woman with no children comes frequently to the clinic for multiple medical problems. She had several brief psychiatric admissions related to anxiety and depression. She has trouble keeping a job. She is a college student but rarely takes more than one course each quarter. Her most common diagnoses are frequent sore throats, asthma, back pain, recurrent headaches, and musculoskeletal pain. Her relationships are tumultuous and shortterm, and she feels victimized by the men in her life. She rarely drinks, but when she does, she drinks to excess. She smokes 3 packs of cigarettes a day. Her family lives nearby but rarely sees her since she accused her father of childhood sexual abuse.

Perhaps these 3 patients give some sense of the suffering experienced by the frequent users of this primary care clinic.

\section{REFERENCES}

1. Goldberg ID, Krantz G, Locke BZ. Effect of a shortterm outpatient psychiatric therapy benefit on the utilization of medical services in a prepaid group practice medical program Med Care 1970;8:419-28.

2. Jameson J, Shuman LJ, Young WW. The effects of outpatient psychiatric utilization on the costs of providing third-party coverage. Med Care 1978;6: 383-99.

3. John C, Schwenk TL, Roi LD, Cohen M. Medical care and demographic characteristics of 'difficult' patients. J Fam Pract 1987;24:607-10.

4. Hahn SR, Kroenke K, Spitzer RL, Brody D, Williams JB, Linzer $M$, et al. The difficult patient: prevalence, psychopathology, and functional impairment. J Gen Intern Med 1996;11:1-8.

5. McFarland BH, Freeborn DK, Mullooly JP, Pope CR. Utilization patterns among long-term enrollees in a prepaid group practice health maintenance organization. Med Care 1985;23:1221-33.

6. Barsky AJ, Wyshak G, Klerman GL. Medical and psychiatric determinants of outpatient medical utilization. Med Care 1986;24:548-60.

7. Katon W, Ries RK, Kleinman A. The prevalence of somatization in primary care. Compr Psychiatry 1984;25:208-15.

8. Katon W, von Korff M, Lin E, Lipscomb P, Russo J, Wagner $\mathrm{E}$, et al. Distressed high utilizers of medical care. DSM-III-R diagnoses and treatment needs. Gen Hosp Psychiatry 1990;12:355-62.

9. Nielsen AC, Williams TA. Depression in ambulatory medical patients: prevalence by self-report questionnaire and recognition by nonpsychiatric physicians. Arch Gen Psychiatry 1980;37:999-1004.

10. Jencks SF. Recognition of mental distress and diagnosis of mental disorder in primary care. JAMA 1985;253:1903-7.

11. Regier DA, Myers JK, Kramer M, Robgins LN, Blazer DG, Hough RL, et al. The NIMH epidemiologic catchment area program. HIstorical context, major objectives, and study population characteristics. Arch Gen Psychiatry 1984;41:934-41.

12. Katon W, Kleinman A, Rosen G. Depression and somatization: a review. Part I. Am J Med 1982;72: 127-35.

13. Katon W, Kleinman A, Rosen G. Depression and 
somatization: a review. Part II. Am J Med;72:241-7.

14. Katon W. Depression: relationship to somatization and chronic medical illness. J Clin Psychiatry 1984;45(3 Pt 2):4-12.

15. Rodin G, Voshart K. Depression in the medically ill: an overview. Am J Psychiatry 1986;143:696-705

16. Oxman TE, Harrigan J, Kues J. Diagnostic patterns of family physicians for somatoform, depressive, and anxiety disorders. J Fam Pract 1983;17:439-46. .

17. System for statistics [computer program]. Evanston,
Ill: Systat, Inc, 1995.

18. Burns N, Grove SK. The practice of nursing research: conduct, critique, and utilization. ed 2. Philadelphia: WB Saunders, 1993:508.

19. Browne GB, Humphrey B, Pallister R, Browne JA, Shetzer L. Prevalence and characteristics of frequent attenders in a prepaid Canadian family practice. J Fam Pract 1982;14:63-71.

20. Report card for Vermont's high schools. Burlington Free Press, 2 Feb 1997:1.

\section{Announcement}

\section{American Board of Family Practice, Inc.}

\section{Certificate of Added \\ Qualifications in Sports Medicine Examination Date: Friday, April 16, 1999}

The Practice Pathway (Plan II) will be available only through the 1999 examination. The Practice Pathway plan will expire after the 1999 examination and only those ABFP Diplomates who satisfactorily complete a one-year sports medicine fellowship will be eligible to apply for the CAQ in Sports Medicine. Specific information concerning the requirements for this examination appears elsewhere in this publication.

Applications for the 1999 examination will be available July 1, 1998.

To request an application write or call:

Sports Medicine Examination American Board of Family Practice, Inc. 2228 Young Drive

Lexington, KY 40505-4294

(606) 269-5626, ext. 264

Toll Free (888) 995-5700, ext. 264

Fax (606) 335-7509

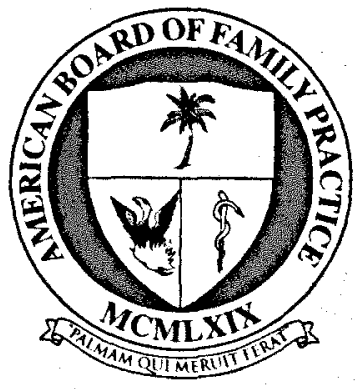

